\title{
Modelos matemáticos para estimação dos parâmetros da cinética de degradação ruminal de concentradosprotéicos ${ }^{1}$
}

\author{
Mathematical models for estimating the parameters of ruminal degradation kinetics of \\ protein concentrates
}

\author{
TEIXEIRA, Ubiara Henrique Gomes ${ }^{2 *}$; SIMIONI, Tiago Adriano ${ }^{2}$; BEZERRA, Rayane \\ Pinho $^{2}$; SOARES, Kaio Augusto Ribeiro Santana Cavalini ${ }^{2}$; ROMUALDO, Thayse \\ Gomes $^{2}$; TORRES, Rodrigo de Nazaré Santos ${ }^{3}$; SILVA, Henrique Melo ${ }^{3}$; PINA, \\ Douglas dos Santos ${ }^{4}$
}

\footnotetext{
${ }^{1}$ Parte da dissertação de mestrado em Zootecnia do primeiro autor, financiada pelo CNPq e FAPEMAT.

${ }^{2}$ Universidade Federal de Mato Grosso, Programa de Pós-Graduação em Zootecnia, Sinop, Mato Grosso, Brasil.

${ }^{3}$ Universidade Federal de Mato Grosso, Sinop, Mato Grosso, Brasil.

${ }^{4}$ Universidade Federal de Mato Grosso, Instituto de Ciência Agrárias e Agricultura, Sinop, Mato Grosso, Brasil.

*Endereço para correspondência: ubiara_zootec@hotmail.com
}

\section{RESUMO}

Objetivou-se com este estudo avaliar os parâmetros da cinética de degradação ruminal dos concentrados protéicos, farelo de soja(FS) e torta de algodão(TA). Para estimativa dos parâmetros da cinética de degradação in situ da matéria seca (MS) e proteína bruta (PB) dos concentrados, foi realizado o ajuste de 5 diferentes modelos matemáticos não-lineares: Exponencial, Van Milgen, Logístico, Gompertz e Richards. Para avaliação in situ dos alimentos, foram utilizados dois bovinos adultoscanuladosno rúmen. As amostras foram incubadas nos tempos $0 ; 2 ; 4 ; 6$; $12 ; 16 ; 24 ; 36 ; 48$ e 72 horas, nos resíduos de incubação foram determinados os teores de MS e $\mathrm{PB}$, e sua degradabilidade potencial e efetiva. Os valores de degradabilidade efetiva da MS do FS foram de 86,35; 74,23 e 65,50\%,e da TA de 53,44; 41,70 e $35,21 \%$ nas taxas de passagem de 0,02 ; 0,05 e $0,08 . \mathrm{h}^{-1}$, respectivamente. O FS e a TA apresentaram valores para a fração $\mathrm{A}$ da $\mathrm{PB}$ de 18,15 e $34,77 \%$ e para a fração B, 79,76 e 55,10\%, respectivamente. De acordo com a ponderação de Akaike (Wi) o modelo de Richards apresenta; 95,45 e $49,64 \%$ de chance de ser o modelo mais adequado, para caracterizar a cinética de degradação in situ da MS do, FS e da TA, respectivamente. Contudo, o modelo de Gompertz apresenta 63,86 e $66,49 \%$ de chance de ser o modelo mais adequado para caracterizar a degradação da PB do FS e TA.

Palavras-chaves: degradabilidade in situ, farelo de soja, torta de algodão

\section{SUMMARY}

This studied aimed to evaluate the parameters of ruminal degradation kinetics of protein concentrates, soybean meal (SM) and cotton cake (CC).To estimate the in situ degradation parameters of $\mathrm{DM}$ and $\mathrm{CP}$ from coproducts were fitted 5different non-linear mathematical models: Exponencial, Van Milgen, Logístico, Gompertz and Richards. For in situ evaluation were used two cattle cannulated in the rumen. The samples were incubate dat $0,2,4,6,12,16$, $24,36,48$ and 72 hours and in the incubation residues were determined $\mathrm{DM}$ and $\mathrm{CP}$ and their degradability. The DM degradability of SM were $86.35,74.23,65.50 \%$ and to $\mathrm{CC}$ were $53.44,41.70$ and $35.21 \%$ in passage rates of $0.02 ; 0.05$ and $0.08 . \mathrm{h}^{-1}$, respectively. The SM and $\mathrm{CC}$ showed values for the $\mathrm{CP}$ soluble fraction of the $18.15,34.77 \%$ and 79.76 , $55.10 \%$ to insoluble potentially degradable fraction, respectively. According to the Akaike weights (Wi) the model of Richards has 95.45 
and $49.64 \%$ of chance to be the most suitable model to characterize the in situ DM degradation of SM and CC. However, the Gompertz model has 63.86 and $66.49 \%$ chance to be the most suitable model to characterize the $\mathrm{CP}$ in situ degradation of SM and CC.

Keywords: cotton cake, degradability, in situ soybeanmeal

\section{INTRODUÇÃO}

As tortas e os farelos são os principais concentrados proteicos resultantes do processamento de grãos de oleaginosas pela indústria do biodiesel, e tem potencial para serem utilizados na alimentação animal, dentre esses, se destacam o farelo de soja e a torta de algodão (ABDALLA et al., 2008; LIMA JÚNIOR et al., 2011). A caracterização química desses concentrados é de extrema importância para sua aplicação na alimentação animal, uma vez que a composição dessas tortas e farelos pode ser decisiva na definição de seus usos potenciais (SOUZA et al., 2009).

A técnica in situ de avaliação de alimentos é uma ferramenta que pode ser utilizada para avaliar a qualidade dos alimentos e prover informações sobre a cinética do processo de degradação ruminal(ØRSKOVET al., 1980). A avaliação da degradabilidade ruminal das diferentes frações dos alimentos permite intensificar a síntese de proteína microbiana, reduzindo perdas de energia, possibilitando maior eficiência no balanceamento de dietas (CARVALHO et al., 2008; GOES et al., 2011).

Para determinação da cinética de degradação ruminal são usados modelos matemáticos não-lineares ajustados aos dados obtidos durante o processo de incubação in situ. Diversos modelos, com pressuposições e tratamentos matemáticos distintos, estão disponíveis para ajuste das curvas de degradação e determinação dos parâmetros cinéticos da degradação in situ, sendo o principal objetivo destes modelos é descrever as alterações do sistema em função do tempo de incubação (HVELPLUND \& WEISBJERG, 2000).

A maioria dos trabalhos referentes a técnicas de avaliação de alimentos tem sido direcionados ao desenvolvimento de novas técnicas e a derivação de modelos matemáticos para descrever a cinética do processo de degradação in situ ou in vitro dos alimentos (BLÜMMEL \& BECKER, 1997). Assim, possibilitando ao pesquisador a escolha do modelo matemático que melhor represente o comportamento biológico das suas observações e ampliando a possibilidade de escolha.

Desta forma, objetivou-se com este estudo avaliar os parâmetros da cinética de degradação ruminal dos concentrados proteicos mais usados na formulação de dietas para ruminantes, farelo soja e torta de algodão, bem como, avaliar diferentes modelos matemáticos para caracterizar o perfil de degradação ruminal destes concentrados proteicos.

\section{MATERIAL E MÉTODOS}

$\mathrm{O}$ experimento foi realizado na Universidade Federal do Mato Grosso (UFMT) campus de Sinop, onde as análises químico-bromatológicas dos coprodutos agroindustriais foram realizados no Laboratório de Nutrição Animal e Forragicultura.

Para avaliação in situ foram utilizados farelo de soja (FS) e torta de algodão (TA). Os alimentos foram desintegrados a $2 \mathrm{~mm}$ de diâmetro, em moinho de facas (Marconi, modelo MA 680) e depois foram armazenados em frascos de plásticos e mantidos em freezer a 
Rev. Bras. Saúde Prod. Anim., Salvador, v.17, n.1, p.73-85 jan./mar., $2016 \quad$ http://www.rbspa.ufba.br ISSN 15199940

temperatura de $-10^{\circ} \mathrm{C}$. As amostras destinadas a caracterização químicobromatologicas (Tabela 1) foram desintegradas em moinho de facas, adaptado com peneira de $1 \mathrm{~mm}$ de diâmetro. Estas, então, foram submetidas à determinação do teor de matéria seca (MS), matéria mineral (MM), matéria orgânica (MO), fibra insolúvel em detergente neutro (FDN), proteína bruta $(\mathrm{PB})$ e extrato etéreo (EE), segundo método descrito por Silva \& Queiroz (2002).

Tabela 1. Composição química-bromatológica do farelo de soja e da torta de algodão

\begin{tabular}{lcc}
\hline \multirow{2}{*}{ Item } & \multicolumn{2}{c}{ Coproduto } \\
\cline { 2 - 3 } & Farelo de soja $(\%)$ & Torta de algodão \\
\hline Matéria Seca & 87,48 & 93,4 \\
Matéria Orgânica* & 92,61 & 93,5 \\
Matéria Mineral* $^{*}$ & 7,4 & 6,5 \\
Proteína Bruta* & 53,2 & 28,01 \\
Fibra detergente Neutro* & 13,69 & 44,09 \\
Extrato Etéreo* & 1,36 & 9,31 \\
\hline
\end{tabular}

*Valores expressos em \% da Matéria seca

Os procedimentos de incubação in situ das amostras foram realizados no Setor de Metabolismo Animal do Programa de Pós-graduação em Zootecnia da UFMT - Sinop. Para isto, foram utilizados dois bovinos mestiços, canulados no rúmen, com peso médio $250 \mathrm{~kg}$ e idade média de 20 meses. Os animais foram alimentados duas vezes ao dia (07:00 e 17:00 horas) sendo fornecido silagem de milho como volumoso exclusivo, milho moído e farelo de soja como concentrado mantendo uma relação volumoso concentrado de 70:30 (com base na MS da dieta). A alimentação foi fornecida em quantidades suficiente para que se obtivesse aproximadamente $10 \%$ de sobras no cocho. Água e mistura mineral foram administradas ad libitum. Amostras dos dois alimentos (FS e TA) foram alocadas em sacos de náilon (R1020 - ANKOM) com porosidade de 50 micras com tamanho de $10 \times 20 \mathrm{~cm}$ e relação média de $20 \mathrm{mg}$ de amostra por $\mathrm{cm}^{2}$ de área superficial dos sacos
(HVELPLUND \& WEISBJERG, 2000). Inicialmente, os sacos de náilon foram aquecidos a $65^{\circ} \mathrm{C}$ em estufa de ventilação forçada por 24 horas e então alocados em dessecador e depois pesados. Posteriormente, os sacos foram preenchidos com seis gramas de amostras dos coprodutos a serem avaliados, utilizando duas amostras de cada alimento por animal e tempo de incubação. As amostras foram incubadas no rúmem, de forma seqüencial, com a finalidade de serem retiradas conjuntamente no final do período de incubação, sendo utilizados os tempos $0 ; 2 ; 4 ; 6 ; 12 ; 16 ; 24 ; 36 ; 48$ e 72 horas, gerando um total de 36 amostras por animal (PINA et al., 2010).

Imediatamente após serem retirados do rúmen, os sacos foram imersos em água fria $\left( \pm 0^{\circ} \mathrm{C}\right)$, e posteriormente lavados, manualmente, em água corrente em temperatura ambiente, até que esta estivesse límpida. As frações solúveis (tempo zero de incubação) foram determinadas por meio dos mesmos procedimentos, porém sem incubação 
ruminal, lavadas somente em água corrente. Após a lavagem os sacos foram secos em estufa de ventilação forçada a uma temperatura de $65^{\circ} \mathrm{C}$, por 72 horas (tempo necessário para atingir a constância de peso), sendo então, levados a um dessecador durante 30 minutos e pesados posteriormente para determinação do resíduo de matéria seca (PASSINI et al., 2004).

Nos resíduos de incubação foram determinados os teores de MS e PB, como descrito anteriormente, de forma a estimar a proporção de desaparecimento destas frações dos alimentos nos respectivos tempos de incubação. Para estimar os parâmetros da cinética de degradação ruminal dos coprodutos avaliados foram utilizados cinco diferentes modelos matemáticos nãolineares: Exponencial, Van Milgen, Logístico, Gompertz e Richards (Tabela 2).

Tabela 2. Modelos matemáticos não lineares avaliados no estudo

\begin{tabular}{|c|c|c|c|}
\hline Item $^{1}$ & $\mathrm{NP}^{2}$ & Restrições & Equações $^{3}$ \\
\hline 1 & 3 & $\mathrm{~A}, \mathrm{~B}$ e $\mathrm{kd} \geq 0$ & $\hat{\mathrm{Y}}=\mathrm{A}+\mathrm{B} *\left(1-\exp ^{-\mathrm{kd}^{*} \mathrm{t}}\right)$ \\
\hline 2 & 3 & & $\hat{\mathrm{Y}}=\mathrm{A}+\mathrm{B} *\left[1-(1+\mathrm{L} * \mathrm{ti}) * \exp ^{\left(-\mathrm{L}^{*} \mathrm{ti}\right)}\right]$ \\
\hline 3 & & & $\hat{\mathrm{Y}}=\mathrm{A}+\mathrm{B} /\left[1+\exp ^{\left(2-4^{*} \mathrm{Kd}^{*}\right)}\right]$ \\
\hline 4 & 3 & $d \geq 0$ & $\hat{\mathrm{Y}}=\mathrm{A}+\mathrm{B}^{*} \exp ^{-\exp \left(1-\mathrm{kd}^{*} \mathrm{t}\right)}$ \\
\hline & 4 & $\mathrm{~A}, \mathrm{~B}$ e $\mathrm{kd} \geq 0$ e $\mathrm{n} \geq-1$ & $\hat{\mathrm{Y}}=\mathrm{A}+(\mathrm{A} * \mathrm{~B}) *\left[\left(\mathrm{~A}^{\mathrm{n}}+\left(\left(\mathrm{B}^{\mathrm{n}}-\mathrm{A}^{\mathrm{n}}\right) * \exp ^{(-\mathrm{kd} * t)}\right)\right]^{(-1 / \mathrm{n})}\right.$ \\
\hline \multicolumn{4}{|c|}{$\begin{array}{l}\text { - } 1=\text { Exponencial (Ørskov et al., 1980); } 2=\text { Van Milgen (Van Milgen et al.,1991); } 3 \text { = Logístico } \\
\text { (France et al., 1996); } 4=\text { Gompertz (France et al., 1996).; } 5=\text { Richards (France et al., 1996). } \\
2 \text { - } \mathrm{NP}=\text { número de parâmetros do modelo. } \\
3 \text { - } \mathrm{A}=\text { fração solúvel }(\%), \mathrm{B}=\text { fração insolúvel potencialmente degradada }(\%), \mathrm{KD}=\text { taxa fracional de } \\
\text { degradação }\left(\mathrm{h}^{-1}\right), \mathrm{t}=\text { tempo de incubação }(\mathrm{h}), \mathrm{L}=\text { taxa fracional conjunta de latência e degradação; } \mathrm{KD}= \\
\mathrm{L} / 2 ; \mathrm{n}=\text { parâmetro sem significado biológico. }\end{array}$} \\
\hline
\end{tabular}

Para estimativa dos parâmetros da cinética de degradação in situ da MS e PB dos alimentos estudados foram realizados os ajustes dos modelos de regressão não-linear, acima descritos, pelo método iterativo de Marquardt inserido no procedimento PROC NLIN do SAS (SAS INSTITUTE, 2005).

A avaliação dos modelos não lineares foi baseada na observação de que os parâmetros estimados não violassem nenhuma das pressuposições do modelo. Na significância dos parâmetros estimados em relação à hipótese de nulidade, no número de corridas de sinais do resíduo, na observação do comportamento entre os valores do resíduo padronizado e os valores preditos pelo modelo, e no valor da raiz quadrada do quadrado médio do resíduo (VIEIRA et al., 2008). Além do critério de ponderação de Akaike (GONÇALVES \& FRITSCHE-NETO, 2012) obtido através do PROC MIXED do SAS(SAS INSTITUTE, 2005).

As degradabilidades efetivas foram calculadas utilizando taxas de passagem (Kp) de 0,02; 0,05 e 0,08.h $\mathrm{h}^{-1}$, para baixo, médio e alto consumos, respectivamente, seguindo o modelo proposto por Ørskov \& McDonald (1979): $\mathrm{DE}=\mathrm{A}+(\mathrm{B} * \mathrm{Kd}) /(\mathrm{Kd}+\mathrm{Kp})$, onde DE é a degradabilidade efetiva, A é a fração solúvel, expressa em porcentagem (\%), B é a fração insolúvel potencialmente degradada, expressa em porcentagem $(\%), \mathrm{Kd}$ é a taxa de degradação da fração insolúvel potencialmente degradada, expresso em porcentagem por hora $\left(\mathrm{h}^{-1}\right)$ e Kp é a taxa 
Rev. Bras. Saúde Prod. Anim., Salvador, v.17, n.1, p.73-85 jan./mar., $2016 \quad$ http://www.rbspa.ufba.br ISSN 15199940

fracional de passagem, expresso em porcentagem por hora $\left(\mathrm{h}^{-1}\right)$.

\section{RESULTADOS E DISCUSSÃO}

Considerando os parâmetros avaliados neste estudo, o modelo mais adequado para caracterizar a cinética de degradação in situ da MS do FS e TA foi o modelo proposto por Richards (FRANCE et al., 1996). Esta determinação foi baseada no menor valor para raiz quadrada do quadrado médio residual, no maior número de corridas de sinal para o resíduo padronizado e no critério de ponderação de Akaike (Tabela 3).

Baseados nos valores de ponderação de Akaike (Wi) o modelo de Richards apresenta 95,45 e $49,64 \%$ de chance de ser o modelo mais adequado, dentre o conjunto de modelos avaliados, para caracterizar a cinética de degradação in situ da MS do FS e da TA, respectivamente. Apresentando valores de 4,3589 e 3,6656 para a raiz do quadrado médio do resíduo para o FS e a TA, respectivamente, e um maior número de corridas de sinais para o resíduo padronizado de 19 e 13 para o FS e TA, respectivamente (Tabela 3 ).

Tabela 3. Parâmetros da cinética de degradaçãoin situ da MS de concentrados protéicos obtidos com diferentes modelos matemáticos não-lineares

\begin{tabular}{|c|c|c|c|c|c|c|c|c|c|c|}
\hline \multirow{2}{*}{ Item } & \multirow{2}{*}{$M^{1}$} & \multicolumn{5}{|c|}{ Parâmetros e Erro Padrão (EP) } & \multirow[b]{2}{*}{ EP } & \multirow[b]{2}{*}{$\mathrm{Wi}$} & \multicolumn{2}{|c|}{ Estatísticas } \\
\hline & & A & EP & $\mathrm{B}$ & EP & $\mathrm{Kd}$ & & & $\mathrm{RR}$ & NS \\
\hline \multirow{5}{*}{ Farelo de Soja } & 1 & 21,09 & 1,92 & 77,75 & 2,21 & 0,0966 & 0,0072 & 2,88 & 4,80 & 15 \\
\hline & 2 & 27,03 & 1,76 & 69,38 & 2,05 & 0,1041 & 0,0122 & 0,16 & 4,96 & 15 \\
\hline & 3 & 18,33 & 1,98 & 77,05 & 2,38 & 0,0665 & 0,0035 & 0,01 & 5,19 & 15 \\
\hline & 4 & 21,18 & 1,81 & 75,16 & 2,14 & 0,1812 & 0,0101 & 1,50 & 4,81 & 16 \\
\hline & 5 & 11,77 & 1,05 & 85,66 & 1,92 & 0,1346 & 0,0246 & 95,45 & 4,36 & 19 \\
\hline \multirow{5}{*}{ Torta de Algodão } & 1 & 25,35 & 1,31 & 43,14 & 1,89 & 0,0542 & 0,0064 & 49,64 & 3,67 & 13 \\
\hline & 2 & 29,08 & 1,48 & 36,76 & 2,04 & 0,0609 & 0,0129 & 0,16 & 4,82 & 5 \\
\hline & 3 & 24,41 & 1,70 & 40,33 & 2,35 & 0,0403 & 0,0038 & 0,06 & 5,07 & 5 \\
\hline & 4 & 25,86 & 1,53 & 39,98 & 2,14 & 0,1064 & 0,0107 & 0,50 & 4,67 & 6 \\
\hline & 5 & 11,35 & 1,31 & 55,81 & 2,14 & 0,0542 & 0,0064 & 49,64 & 3,67 & 13 \\
\hline
\end{tabular}

${ }^{\mathrm{I}} \mathrm{M}=$ modelos: 1 = Exponencial, 2 = Van Milgen, 3 = Logístico, 4 = Gompertz e 5 = Richards.

$\mathrm{A}=$ fração solúvel; $\mathrm{B}=$ fração insolúvel potencialmente degradada; $\mathrm{Kd}=$ taxa de degradação da fração $\mathrm{B} ; \mathrm{RR}=$ raiz do quadrado médio do resíduo e $\mathrm{NS}$ = número de corridas de sinais do resíduo.

${ }^{2}$ Ponderação de Akaike em \%.

O modelo de Richards, o qual foi o que melhor caracterizou o perfil de degradação ruminal da MS da TA e do FS, estimou frações solúveis semelhantes $(12,67$ e $11,77 \%)$ para os alimentos, porém o FS apresentou maior fração do alimento insolúvel potencialmente degradável $(85,66 \%)$ e maior taxa de degradação para esta fração $\left(0,1346 \cdot \mathrm{h}^{-1}\right)$ em relação aos parâmetros determinados para a TA $\left(55,81 \% ; 0,0542 \cdot \mathrm{h}^{-1}\right)$, respectivamente. Avaliando a degradabilidade ruminal do FS pelo ajuste do modelo exponencial Goes et al. (2008) encontraram valores de $32,85 \%$ para a fração $\mathrm{A}, 65,75 \%$ para a fração $B$ e para a taxa de degradação $0,0865 \cdot h^{-1}$. Valores de 35,64 
$\%$ e $36,5 \%$ para as frações A e B do Farelo de algodão foram reportados Beran et al. (2005), também através do ajuste do mesmo modelo.

A qualidade do ajuste do modelo de Richards aos dados de degradação in situ da MS da TA e do FS podem ser visualizados nas Figuras 1 e 2, respectivamente. O comportamento do resíduo padronizado em função dos valores preditos pelo modelo de Richards apresentou estrutura dispersa, não evidenciando nenhuma tendência de sub ou superestimação dos valores de degradação para ambos os alimentos.

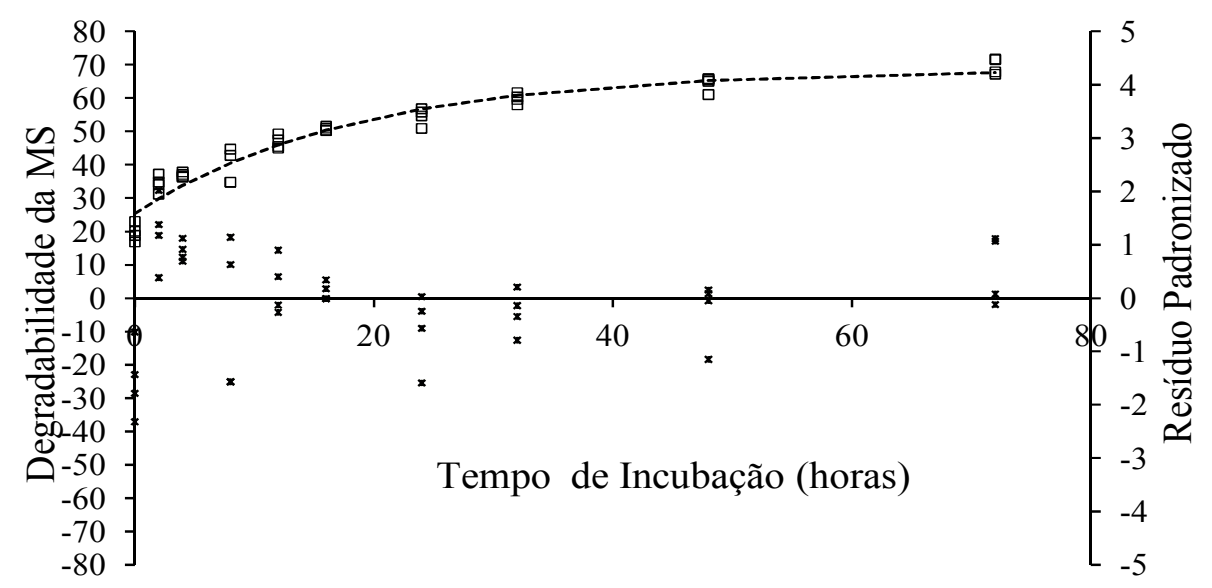

Figura 1. Perfil de degradação in situ da MS da Torta de Algodão caracterizado pelo modelo Richards ( $\square$ degradabilidade mensurada)

A eficiência de ajuste do modelo de Richards aos dados de degradação ruminal da MS do FS e TA, pode ser observada pela relação entre os valores preditos pelo modelo, delimitados pela linha de tendência e os valores obtidos no ensaio de digestão in situ ( $\square$ e $\diamond$ para o TA e FS, respectivamente). Desta forma, corroborando com os demais indicadores: menor valor para raiz quadrada do quadrado médio residual e maior número de corridas de sinal para o resíduo padronizado e maior proporção para a ponderação de Akaike (Tabela 3).

Os valores de degradabilidade efetiva da MS do FS (86,35; 74,23 e 65,50\%) foram maiores que os valores encontrados para a
TA $(53,44 ; 41,70$ e $35,21 \%)$ para as taxas de passagem de 0,$02 ; 0,05$ e $0,08 . \mathrm{h}^{-1}$, respectivamente. Apesar do FS e a TA terem apresentados valores semelhantes para a fração A (11,77 e 12,67 \%, respectivamente), a fração $\mathrm{B}$ e o $\mathrm{Kd}$ do FS de $85,66 \%$ e $0,1346 . h^{-1}$ foram superioresaos valores obtidos para a TA $\left(55,81 \%\right.$ e $\left.0,0542 \cdot h^{-1}\right)$. Estes resultados refletem a maior degradabilidade efetiva da MS do FS em relação a TA, evidenciando que o modelo de Richards também reflete comportamento biológico compatível com as observações in vivoenão apresenta somente melhores índices estatísticos utilizados para mensurar a qualidade de ajuste dos modelos (Tabela 4). 


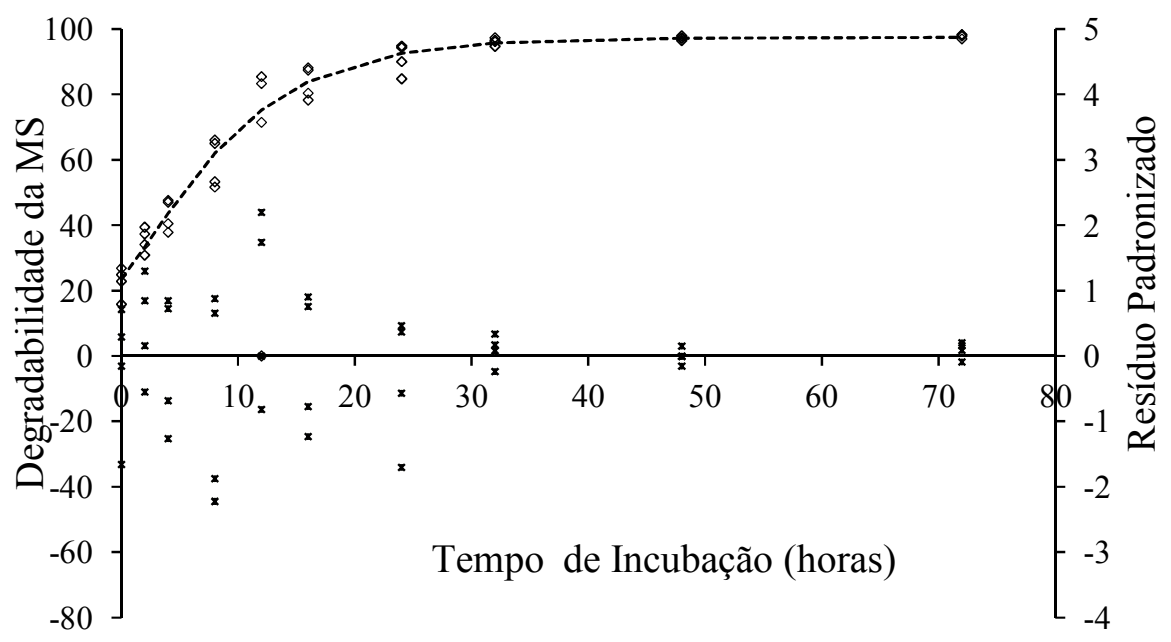

Figura 2. Perfil de degradação in situ da MS do Farelo de Soja caracterizado pelo modelo de Richards $(\diamond$ degradabilidade mensurada)

Tabela 4. Parâmetros da cinética de digestão in situ da $\mathrm{MS}$ (A, B e Kd) e degradabilidade efetiva da MS nas taxas de passagens $0,02,0,05$ e $0,08 . \mathrm{h}^{-1}$ de diferentes concentrados protéicos

\begin{tabular}{|c|c|c|c|c|c|c|c|}
\hline \multirow{2}{*}{ Alimentos } & \multirow{2}{*}{ Modelos } & \multirow{2}{*}{ A } & \multirow{2}{*}{ B } & \multirow{2}{*}{$\mathrm{Kd}$} & \multicolumn{3}{|c|}{ Degradabilidade Efetiva } \\
\hline & & & & & 0,02 & 0,05 & 0,08 \\
\hline Farelo de Soja & Richards & 11,77 & 85,66 & 0,1346 & 86,35 & 74,23 & 65,50 \\
\hline Torta de Algodão & Richards & 12,67 & 55,81 & 0,0542 & 53,44 & 41,70 & 35,21 \\
\hline
\end{tabular}

Valores de degradabilidade efetiva da MS do FS de 90,29; 83,01 e 77,25\% foram reportados por Morgulis et al. (1997), os quais são superiores aos valores de degradabilidade efetiva $(86,35 ; 74,23$ e $65,50 \%)$ para as taxas de passagem 0,$02 ; 0,05$ e $0,08 \mathrm{~h}^{-1}$, respectivamente. Ao avaliar os dados de Cabral et al. (2005) para as frações A $(32,55 \%), \mathrm{B}(67,45 \%)$ e $\mathrm{Kd}\left(0,1144 . \mathrm{h}^{-}\right.$ $\left.{ }^{1}\right)$ e calcular a degradabilidade efetiva da MS do FS, é possível observar resultados de 89,96; 79,49 e 72,24\% também, ligeiramente, superiores aos resultados de degradabilidade efetiva da MS do FS.
Os resultados de degradabilidade efetiva da MS da TA $(56,86 ; 47,79$ e $42,77 \%)$ estão próximos aos valores encontrados por Souza et al. (2000) que apresentaram valores de degradabilidade efetiva da MS do farelo de algodão de 64,94; 52,39 e $46,30 \%$ para as taxas de passagens de 0,$02 ; 0,05$ e $0,08 . \mathrm{h}^{-1}$, respectivamente. Garcia et al. (2003) trabalhando com degradabilidade in situ de concentrados protéicos, ao avaliar o farelo de algodão reportou valores de 61,12; 51,91 e $46,63 \%$ também próximos aos encontrados para a TA.

Baseados nos parâmetros avaliados, o modelo mais adequado para caracterizar a cinética de degradação in situ da PB 
dos alimentos (FS e TA) foi o proposto por Gompertz (FRANCE et al., 1996). Esta determinação foi baseada no menor valor para raiz quadrada do quadrado médio residual, maior número de corridas de sinal para o resíduo padronizado e no critério de ponderação de Akaike, o qual indicou a probabilidade do modelo de Gompertz ser o mais adequado em relação ao conjunto de modelos avaliados (Tabela 5).
O FS e a TA apresentaram valores para a fração A da PB de 18,15 e $34,77 \%$ e para a fração B de, 79,76 e 55,10\%, respectivamente. Apresentando o FS menor fração solúvel para $\mathrm{PB}$ e maior fração insolúvel potencialmente degradável em relação a TA (Tabela 5). Porém a taxa de degradação para a fração B do FS de 0,1822 . $^{-1}$ não diferiu da taxa de degradação da fração $B$ da TA de $0,1872 \cdot h^{-1}$ (Tabela 5).

Tabela 5. Parâmetros da cinética de digestão in situ da PB de concentrados protéicos obtidos com diferentes modelos matemáticos não-lineares

\begin{tabular}{|c|c|c|c|c|c|c|c|c|c|c|}
\hline \multirow{2}{*}{ Item } & \multirow{2}{*}{$\mathrm{M}^{1}$} & \multicolumn{7}{|c|}{ Parâmetros e erro padrão (EP) } & \multicolumn{2}{|c|}{ Estatísticas } \\
\hline & & A & EP & $\mathrm{B}$ & EP & $\mathrm{Kd}$ & EP & Wi & RR & NS \\
\hline \multirow{5}{*}{ Farelo de Soja } & 1 & 18,04 & 2,93 & 82,30 & 3,36 & 0,0980 & 0,0105 & 10,56 & 7,2908 & 15 \\
\hline & 2 & 24,36 & 2,55 & 73,60 & 2,96 & 0,1047 & 0,0084 & 15,75 & 7,1709 & 15 \\
\hline & 3 & 15,12 & 2,74 & 81,85 & 3,29 & 0,0666 & 0,0045 & 9,09 & 7,1694 & 15 \\
\hline & 4 & 18,15 & 2,66 & 79,76 & 3,14 & 0,1822 & 0,014 & 63,86 & 7,0295 & 17 \\
\hline & 5 & 11,00 & 1,54 & 87,35 & 2,78 & 0,1616 & 0,0444 & 0,74 & 7,0613 & 17 \\
\hline \multirow{5}{*}{ Torta de Algodão } & 1 & 28,62 & 3,63 & 61,99 & 3,61 & 0,1225 & 0,0184 & 1,10 & 7,7647 & 13 \\
\hline & 2 & 38,95 & 3,16 & 50,78 & 3,55 & 0,1095 & 0,0150 & 31,40 & 8,2246 & 5 \\
\hline & 3 & 33,38 & 3,66 & 56,76 & 4,41 & 0,0593 & 0,0072 & 0,01 & 9,3614 & 5 \\
\hline & 4 & 34,77 & 3,29 & 55,10 & 3,78 & 0,1872 & 0,0245 & 66,49 & 8,1107 & 17 \\
\hline & 5 & 14,31 & 1,63 & 76,30 & 2,51 & 0,1225 & 0,0184 & 1,00 & 7,7647 & 17 \\
\hline
\end{tabular}

${ }^{\mathrm{T}} \mathrm{M}$ = Modelos: 1 = Exponencial, 2 Van Milgen, 3 = Logístico, 4 = Gompertz e 5 = Richards.

A = Fração solúvel; $\mathrm{B}=$ Fração insolúvel potencialmente degradada; $\mathrm{Kd}=$ Taxa de degradação da fração $\mathrm{B} ; \mathrm{RR}=$ Raiz do quadrado médio do resíduo e $\mathrm{NS}$ = Número de corridas de sinais do resíduo.

${ }^{2}$ Ponderação de Akaike em \%.

Estudando a degradabilidade in situ da PB do FS e do farelo de algodão, Moreira et al. (2003) reportaramvalores de $4,03 \%, 97,47 \%$ e $0,1045 . \mathrm{h}^{-1}$ para as frações A, B e Kd do FS e de 32,25\%, $71,35 \%$ e $0,0435 \cdot \mathrm{h}^{-1}$ para as respectivas frações do farelo de algodão. Beran et al. (2005) trabalhando com degradabilidade in situ da PB do FS e farelo de algodão encontraram valores de 43,54 e 54,73\% para as frações A e B do FS e para o farelo de algodão valores de 33,40 e
37,29\%, respectivamente. Desta forma, existe significante variabilidade nos parâmetros da cinética da degradação in situ do FS e da TA, estando os valores dos parâmetros obtidos pelo modelo de Gompertz dentro desta faixa de variação reportada na literatura. A qualidade de ajuste do modelo de Gompertz aos dados de degradação in situ da PB da TA e do FS podem ser visualizados nas Figuras 3 e 4, respectivamente. 


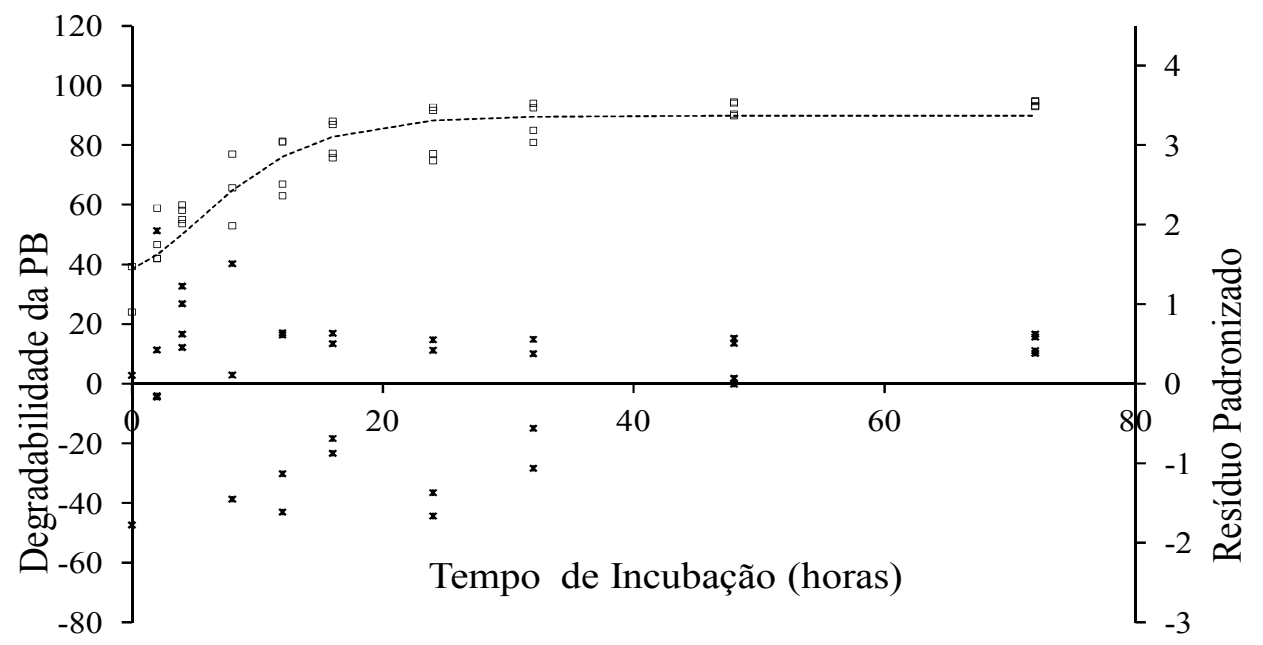

Figura 3. Perfil de degradação in situ da PB da Torta de Algodão caracterizado pelo modelo de Gompertz ( $\square$ degradabilidade mensurada)

O comportamento do resíduo padronizado em função dos valores preditos pelo modelo Gompertz apresentou estrutura dispersa, não evidenciando nenhuma tendência de sub ou superestimação dos valores de degradação para ambos os alimentos. A eficiência de ajuste do modelo de Gompertz aos dados de degradação ruminal da $\mathrm{PB}$ do FS e TA, pode ser visualizada pela relação entre os valores preditos pelo modelo, delimitados pela linha de tendência, e os valores obtidos no ensaio de digestão in situ ( $\square$ e $\diamond$ para o TA e FS, respectivamente), conforme apresentado na Figura 4. Desta forma, corroborando com os demais indicadores (Tabela 5), para determinar que o modelo de Gompertz foi o mais adequado para caracterizar o perfil de degradação in situ da PB destes dois alimentos.

As frações A, B, Kd determinadas com omodelo que melhor se ajustou aos dados de degradação ruminal da PB dos alimentos FS e TA avaliados foram utilizados para estimara degradabilidade efetiva dos mesmos e seus respectivos teores de proteína degradada no rúmem (PDR) e proteína não degradada no rúmem (PNDR), nas taxas de passagem de $0,02,0,05$ e $0,08 \cdot h^{-1}$ (Tabela 6).

Teores de PDR determinados para o FS foram de 90,$02 ; 80,74$ e $73,56 \%$ e para a TA de 84,$55 ; 78,26$ e $73,37 \%$ nas taxas de passagem de 0,$02 ; 0,05$ e 0,08.h-1, respectivamente.Valores estes, superiores aos valores de 79,65; 65,37 e $57,88 \%$ de PDR para o FS reportados por Carvalho et al. (2009) e de 70,35; 52,83 e $44,50 \%$ reportados por Goes et al. (2011) nas taxas de passagem de 0,$02 ; 0,05$ e $0,08 \cdot \mathrm{h}^{-1}$, respectivamente.

Avaliando a cinética da degradação ruminal do farelo de algodão, Oliveira et al. (2005) reportaram valores de PDR de 50,$21 ; 39,88$ e $34,32 \%$, para as taxas de passagem de 0,$02 ; 0,05$ e $0,08 . \mathrm{h}^{-1}$, respectivamente. Estes valores são inferiores aos valores encontrados para a TA. Tal observação se deve aos valores das frações A $(15,8 \%)$, B $(48,2 \%)$ e $\operatorname{Kd}\left(0,0499 \cdot \mathrm{h}^{-1}\right)$ encontrados por Oliveira et al. (2005), os quais são inferiores aos observados. 


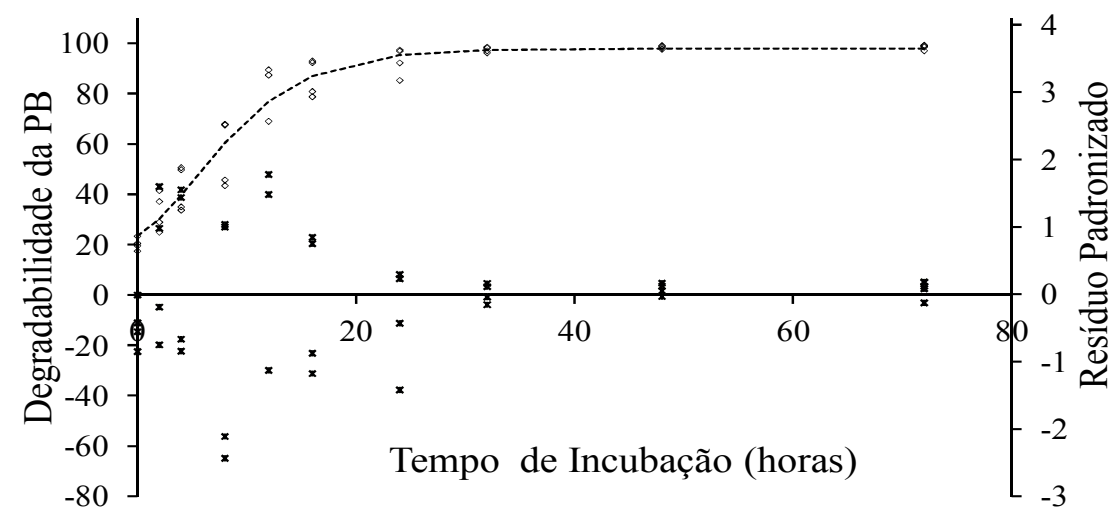

Figura 4. Perfil de degradação in situ da PB do Farelo de Soja caracterizado pelo modelo de Gompertz $(\diamond$ degradabilidade mensurada)

Tabela 6. Parâmetros da cinética de digestão in situ da PB (A, B, Kd) e degradabilidade efetiva da proteína degradada no rúmem (PDR) e proteína não degradada no rúmem (PNDR) nas taxas de passagens $0,02,0,05$ e $0,08 . \mathrm{h}^{-1}$ de diferentes concentrados protéicos

\begin{tabular}{|c|c|c|c|c|c|c|c|c|c|c|}
\hline \multirow{3}{*}{ Alimentos } & \multirow{3}{*}{ Modelos } & \multirow{3}{*}{ A } & \multirow{3}{*}{$\mathrm{B}$} & \multirow{3}{*}{$\mathrm{Kd}$} & \multicolumn{6}{|c|}{ Degradabilidade Efetiva } \\
\hline & & & & & \multicolumn{3}{|c|}{ PDR } & \multicolumn{3}{|c|}{ PNDR } \\
\hline & & & & & 0,02 & 0,05 & 0,08 & 0,02 & 0,05 & 0,08 \\
\hline F. Soja & Gompertz & 18,15 & 79,76 & 0,1822 & 90,02 & 80,74 & 73,57 & 9,98 & 19,26 & 26,43 \\
\hline T. Algodão & Gompertz & 34,77 & 55,10 & 0,1872 & 84,55 & 78,26 & 73,37 & 15,45 & 21,74 & 26,63 \\
\hline
\end{tabular}

Esta variação em relação aos valores dos parâmetros da cinética de degradação ruminal da $\mathrm{MS}$ e $\mathrm{PB}$, reportados na literatura para os concentrados agroindustriais, pode ser devido variação na composição químico-bromatológica destes, o que influência diretamente a eficiência em formulação de dietas para ruminantes e, consequentemente, no desempenho animal, fazendo-se necessário para uma formulação criteriosa a determinação prévia destes parâmetros (PINA et al., 2010).

Segundo Broderick \& Cochran (2000), apesar da grande amplitude de utilização do método in situ para determinação da degradabilidade ruminal dos alimentos, existe ainda uma grande variação nos resultados obtidos em diferentes laboratórios, sendo que, as principais fontes de variação são: tipos de amostras e animal, replicação, condições de incubação, técnica de lavagem, e obtenção de um número relativamente pequeno de pontos por parâmetro estimado nos modelos matemáticos. Dessa forma, a padronização da técnica é de suma importância para permitir uma avaliação adequada dos alimentos e uma 
Rev. Bras. Saúde Prod. Anim., Salvador, v.17, n.1, p.73-85 jan./mar., $2016 \quad$ http://www.rbspa.ufba.br ISSN 15199940

comparação dos resultados obtidos em diferentes laboratórios.

Contudo, a técnica in situ de avaliação de alimentos é uma ferramenta que pode ser utilizada para avaliar a qualidade dos alimentos e prover informações sobre a cinética do processo de degradação que ocorre no rúmen. $\mathrm{O}$ uso da técnica in situ possui a vantagem de permitir uma rápida estimativa da taxa e extensão da degradação ruminal dos alimentos sem a necessidade de procedimentos sofisticados ou complicados (ØRSKOV et al., 1980).

Segundo Blümmel \& Becker (1997), a maioria dos trabalhos referentes a técnicas de avaliação de alimentos tem sido direcionados ao desenvolvimento de novas técnicas e a derivação de modelos matemáticos paradescrever a cinética do processo de degradação in situ ou in vitro dos alimentos. Dessa forma, possibilitando ao pesquisador a escolha do modelo matemático que melhor represente o comportamento biológico das suas observações e ampliando a possibilidade de escolha.

A partir das informações descritas, conclui-se que o modelo proposto por Richards mostra-se o mais adequado para caracterizar o perfil de degradação ruminal da matéria seca do farelo de soja eda torta de algodão. Contudo, o modelo de Gompertz mostra-seo mais adequado para caracterização do perfil de degradação ruminal da proteína bruta dos alimentos avaliados.

\section{AGRADECIMENTOS}

Os autores agradecem ao Conselho Nacional de Desenvolvimento Científico e Tecnológico $(\mathrm{CNPq})$ e a Fundação de Amparo à Pesquisa do Estado de Mato Grosso pelo apoio financeiro na condução deste trabalho.

\section{REFERENNCIA}

ABDALLA, A.L.; FILHO, J.C.S.; GODOI, A.R.; CARMO, C.A., EDUARDO, J.L.P. Utilização de subprodutos da indústria de biodiesel na alimentação de ruminantes. Revista Brasileira de Zootecnia, v.37, p.258260, 2008.

BERAN, F.H.B.; SILVA, L.D.F.; RIBEIRO, E.L.A.; CASTRO, V.S.; CORREA R. A.; KAGUEYAMA, Ê.O.; ROCHA, M.A. Degradabilidade ruminal "in situ" da matéria seca, matéria orgânica e proteína bruta de alguns suplementos concentrados usados na alimentação de bovinos.

Semina: Ciências Agrárias, v.26, n.3, p.405-418, 2005.

BLÜMMEL, M.; BECKER, K. The degradability characteristics of fiftyfour roughages and roughage neutral detergent fibres as described by in vitro gas production and their relationship to voluntary feed intake. British Journal of Nutrition, v.77, p.757-768, 1997.

BRODERICK, G.A.; COCHRAN, R.C. In vitro and In situ methods for estimating digestibility with reference to protein degradability. In:

THEODOROU, M. K. and FRANCE, J. Feeding Systems and Feed Evaluation Models. Wallingford, UK: CAB International, 2000. p. 53-85.

CABRAL, L.S.; VALADARES FILHO, S.C.; ZERVOUDAKIS, J.T.; SOUZA, A.L.; DETMANN, E.

Degradabilidade in situ da matéria seca, da proteína bruta e da fibra de alguns alimentos. Pesquisa Agropecuária Brasileira, v.40, n.8, p.777-781, 2005. 
Rev. Bras. Saúde Prod. Anim., Salvador, v.17, n.1, p.73-85 jan./mar., $2016 \quad$ http://www.rbspa.ufba.br ISSN 15199940

CARVALHO, G.G.P.; PIRES, A.J.V.; GARCIA, R.; VELOSO, C.M.; SILVA, R.R.; MENDES, F.B.L.; PINHEIRO, A.A.; SOUZA, D.R. Degradabilidadein situ da matéria seca, da proteína bruta e da fração fibrosa de concentrados e subprodutos agroindustriais. Ciência Animal Brasileira, v.10, n.3, p.689697, 2009.

CARVALHO, G.G.P.; GARCIA, R.; PIRES, A.J.V.; DETMANN, E.; PEREIRA, O. G.; FERNANDES, F.E.P. Degradação ruminal de silagem de capim-elefante emurchecido ou com diferentes níveis de farelo de cacau.

Revista Brasileira de Zootecnia, v.37, n.8, p.1347-1354, 2008.

FRANCE, J.; DIJKSTRA, J.; DHANOA, M. S. Growth functions and their application in animal Science. Ann Zootech, v.45, p.165-174, 1996. Suppl.

GARCIA, J.; ALCALDE, C.R.; JOBIM, C.C.; ZAMBOM, M.A.; DAMASCENO, J.C.; SANTOS, V.C. Degradabilidadein situ de alimentos concentrados e do capim Brachiaria decumbens Stapf. em diferentes crescimentos vegetativos. Acta Scientiarum. Animal Sciences, v.25, n.2, p.387-395, 2003.

GOES, R.H.T.B.; SOUZA, K.A.; NOGUEIRA, K.A.G.; PEREIRA, D.F.; OLIVEIRA, E.R.; BRABES, K.C.S. Degradabilidade ruminal da matéria seca e proteína bruta, e tempo de colonização microbiana de oleaginosas, utilizadas na alimentação de ovinos. Acta

Scientiarum. Animal Sciences, v.33, n.4, p.373-378, 2011.

GOES, R.H.T.B.; TRAMONTINI, R.C.M.; ALMEIDA, G.D.; CARDIM, S.T.; RIBEIRO, J.; OLIVEIRA, L.A.; MOROTTI, F.; BRABES, K.C.S.; OLIVEIRA, E.R. Degradabilidade ruminal da matéria seca e proteína bruta de diferentes subprodutos agroindustriais utilizados na alimentação de bovinos. Revista Brasileira Saúde Produção Animal [online], v.9, n.3, p.715-725, 2008 .

GONÇALVES, M.C.; FRITSCHENETO, R. Tópicos especiais em biometria no melhoramento de plantas. Visconde do Rio Branco, MG: Suprema, 2012. 282p.

HVELPLUND, T.; WEISBJERG, M.R. In Situ techniques for the estimation of protein degradability and postruminal availability. In: GIVENS, D.I.; OWEN, E.; AXFORD, R.F.E.; OMED, H.M.

Forage Evaluation in Ruminant Nutrition. Wallingford, UK: CAB International, 2000. p. 233-257.

LIMA JÚNIOR, D.M.; BRAGA, A.P.; RANGEL, A.H.N.; BRAGA, Z.C.A.C.; BARRETO, H.F.M.; MACIEL, M.V. Farelo de algodão (gossipum spp.) extrusado na dieta de ruminantes: consumo e digestibilidade. Acta Veterinaria Brasilica, v.5, n.1, p.6875, 2011.

MOREIRA, J.F.C.; RODRÍGUEZ, N.M.; FERNANDES, P.C.C.; VELOSO, C.M.; SALIBA, E.O.S.; GONÇALVES, L.C.; BORGES, I.; BORGES, A.L.C.C. Concentrados protéicos para bovinos. 1 .

Digestibilidade in situ da matéria seca e da proteína bruta. Arquivo Brasileiro Medicina Veterinária e Zootecnia, v.55, n.3, p.315-323, 2003.

MORGULIS, S.C.F.; LUCCI, C.S.; MELOTTI, L. Degradabilidade ruminal do farelo de algodão e da soja crua em bovinos recebendo bagaço de cana-deaçúcar submetido a tratamentos alcalinos. Brazilian Journal of Veterinary Researchand Animal Science, v.34, n.3, p.159-162, 1997. 
Rev. Bras. Saúde Prod. Anim., Salvador, v.17, n.1, p.73-85 jan./mar., $2016 \quad$ http://www.rbspa.ufba.br ISSN 15199940

OLIVEIRA, E.R.; PAIVA, P.C.A.; BANYS, V.L.; ANDRADE, I.F.; LOZANO, D.M. Cinética da digestão ruminal, de dietas compostas com cama de frangos, utilizando como substrato a casca de café, em bovinos.Ciência Animal Brasileira, v.6, n.1, p.11-18, 2005.

ØRSKOV, E. R.; HOVELL, F.D. de B.; MOULD, F. The use of the nylon bag technique for the evaluation of feedstuffs. Tropical Animal

Production, v.5, n.3, p.195-213, 1980.

ØRSKOV, E.R.; McDONALD, I. The estimation of protein degradability in the rumen from incubation measurements weighted according to rate of passage . Journal of Agricultural Science, v.92, p.499-503, 1979.

PASSINI, R.; BORGATTI, L.M.O.; FERREIRA, F.A.; RODRIGUES, P.H.M. Degradabilidade no rúmen bovino de grãos de milho processados de diferentes formas. Pesquisa, Agropecuária Brasileira, v.39, n.3, p.271-276, 2004.

PINA, D.S.; VALADARES, R.F.D.; VALADARES FILHO, S.C.;

CHIZOTTI, M.L. Degradação ruminal da proteína dos alimentos e síntese de proteína microbiana. In: VALADARES FILHO, S. C., MARCONDES, M. I., CHIZOTTI, M. L., PAULINO, P. V. R. Exigências Nutricionais de Zebuínos Puros e Cruzados BR-Corte. 2.ed. Viçosa MG: UFV, 2010. p.13-45.

SAS INSTITUTE. SAS system for windows: versão 9.0. Cary: SAS Institute, 2005.
SILVA, D.J.; QUEIROZ, A.C. Análises de alimentos: métodos químicos e biológicos. 3.ed. Viçosa, MG:

Universidade Federal de Viçosa, 2002. $235 \mathrm{p}$.

SOUZA, A.D.V.; FÁVARO, S.P.; ÍTAVO, L.C.V. ROSCOE, E.

Caracterização química de sementes e tortas de pinhão?manso, nabo? forrageiro e crambe. Pesquisa Agropecuária Brasileira, v.44, n.10, p.1328-1335, 2009.

SOUZA, J.R.S.T.; CAMARÃO, A.P.; RÊGO, L.C. Degradabilidade ruminal da matéria seca e proteína bruta de subprodutos da agroindústria, da pesca e de abatedouros em caprinos. Brazilian Journal of Veterinary Research and Animal Science, v.37, n.2, p.169-174, 2000 .

VAN MILGEN, J.; MURPHY, M.R.; BERGER, L.L. A Compartmental Model to Analyze Ruminal Digestion. Journal of Dairy Science, v.74, n.8, p.2515-2529, 1991.

VIEIRA, R.A.M.; TEDESCHI, L.O.; CANNAS, A. A generalized compartmental model to estimate the fiber mass in the ruminoreticulum: 1, Estimating parameters of digestion. Journal of Theoretical Biology, v.255, p.345-356, 2008.

Data de recebimento: $15 / 05 / 2015$

Data de aprovação: 02/11/2015 